Heaney, R., Foster, F. D., Gregor, S., O'Neill, T., \& Wood, R. (2010). Are two heads better than one? An experiment with novice share traders. Australian J ournal of Management, 35(2), 119-143.

(c) The Author(s) 2010

This is pre-copy-editing, author-produced version of an article accepted for publication in Australian J ournal of Management, following peer review. The definitive published version (see citation above) is located on the abstract page of the publisher, Sage.

This version was made available in the UWA Research Repository the $5^{\text {th }}$ of November 2014 , in compliance with the publisher's policies on archiving in institutional repositories.

Use of the article is subject to copyright law. 


\title{
Are Two Heads Better Than One? An Experiment with Novice Share Traders
}

\author{
Richard Heaney \\ RMIT University* \\ F. Douglas Foster, Shirley Gregor, and Terry O'Neill \\ The Australian National University \\ Robert Wood \\ Melbourne Business School
}

November 2009

\begin{abstract}
We compare the performance of individual and two-person teams in an electronic share trading task. Trader profits are negatively related to the amount of trader market activity and positively related to trader confidence. While we find no evidence of a difference in trading profit between individual and team traders, profit volatility is more sensitive to trading activity for teams. Team trading profit is positively related to attitude and negatively related to perceptions of the difficulty of the task, with overall team trading activity negatively related to views of team members' abilities.
\end{abstract}

JEL Code: D44, G14

Key words: share market trading, teams versus individual trading

\section{Acknowledgements}

We would like to thank those students that took part in the experiment and we would also like to thank the ANU for providing access to students, staff and facilities. This research was funded under an ARC Discovery grant (DP0343994). Comments from an anonymous referee and the editor greatly improved the paper.

\section{Contact Author}

* Richard Heaney, School of Economics and Finance, Business, RMIT, Level 12, 239 Bourke Street, Melbourne, Australia, 3000, Richard.Heaney@ rmit.edu.au, Phone: +61 39925 5905, Fax: +61 399255986 


\section{Introduction}

The use of teams in the workplace has long been widespread (Byrne (1993)) and there is considerable evidence that teams learn faster (Kocher and Sutter (2005)), work more strategically (Cooper and Kagel (2005)), and are better able to adapt to changes in task payoffs (Byrne (1993)) than individuals. Research into the effectiveness of teams has shown that these beneficial effects are mediated through team processes and by a team's assessment of their capability for the task at hand (Gibson, (1999; 2003)). In particular, the level of confidence that team members have about their ability to work together to complete successfully the task, which is referred to as team efficacy (Bandura (1997)), has been found to be an important predictor of team performance on a range of different tasks (Gully, Incalcaterra, Joshi and Beaubien (2002)). The effects of team efficacy have not been tested in a dynamic complex task like stock trading; however (with some qualifications noted below) we would expect the results observed on work tasks to generalise to stock trading.

This paper reports differences in trading activity (measured as the number of buys, sells, bids, asks, and order cancellations) and profits (measured as end of session "cash" balances) between two-person teams and individuals trading in a simulated share market. Our results show higher average trading profits for teams, but this difference is not statistically significant. Further, there is evidence that the volatility of trading profit is more sensitive to trading activity for teams than for individuals. More detailed analysis of team behaviour suggests that team profitability is a function of their trading activity, group attitude, and the perceived difficulty of the task. Further, team trading activity is negatively related to views of the other team member's abilities, suggesting that more cohesive teams tend to trade less. This is 
important, given our finding that lower trading levels are associated with greater trading profits.

Interestingly, self-efficacy, which is the individual level confidence that a subject can execute a task effectively, has also been found to be a significant predictor of individual performance on a wide range of tasks (Stajkovic and Luthans (1998); Bandura (1978, 1997)), including dynamic, complex decisions (Wood and Bandura (1989)). These results are in contrast to those found in studies of trading where confidence has been shown to be associated with over-trading and sup-optimal performance, measured by lower share returns (see, for example, Odean (1999)). However, self-efficacy and team efficacy differ from the conceptualisation and measurement of confidence adopted in previous behavioural finance studies, where confidence has been focused on a person's belief in their general capability to succeed (Odean (1999)). Self-efficacy and team efficacy focus on confidence in relation to the specifics of a task, which in the case of trading include confidence for specific activities such as 'setting a bid' or 'pricing a share'. The difference is that the confidence assessment for self-efficacy and team efficacy requires the person to think about the task and their capabilities with respect to specific activities.

Studies of the decision-making processes of stock trading clubs provide insights into how teams reach their 'buy and sell' decisions. Barber, Heath and Odean (2003) studied stock club trading where groups of investors meet on a regular basis to make stock investments, and compared trades executed by individual traders with those of stock club traders. Groups were more likely to make stock selections on the basis of "ranking by good reasons" and were more likely to favour the most admired companies than individual traders in their decision. Barber, Heath and Odean (2003) found that stock club investments differed significantly from those made by 
individuals. Despite what they described as a more systematic approach by the stock clubs, teams underperformed relative to individual investors after costs (see also Odean (1999); Barber and Odean (2000a; 2000b)). Thus teams may appear to be more deliberate in their decisions than individuals, but this may not result in improved profits; particularly when team decisions lead to investment in well-known, wellunderstood, and heavily traded shares whose price is most likely to reflect value.

While there has been little analysis of team performance in professional financial settings Prather and Middleton (2002) and Prather, Middleton and Cusack (2001) consider differences in risk-adjusted returns to professionally managed investment funds. Using US and Australian investment (mutual) fund data they find no significant differences between funds that had a single investment manager and those that had multiple managers. Using Australian data they also note that individual managers appear to have a slightly wider range of performance (higher maximum values and lower minimum values, as well as larger standard deviations of for estimated selection and timing measures). While their results suggest no substantive return differences to investors, the process by which teams and individuals generate returns may be different.

Teams can also have a moderating influence on decisions. Adams and Ferreira (2009) look at guesses of ice breakup dates for the Tanana River in Alaska. They compare group and individual guesses and note that distribution of group guesses are closer to historical data, and have less variability and less mass in the tail than do individual guesses. They note that this is consistent with moderation or compromise in groups. Adams and Ferreira (2009) also point out that groups are affected by a membership effect - those with more extreme views are more likely to submit individual guesses than join a group. 
Our research extends existing work by studying decisions of novice traders using different forms of confidence, i.e. self-efficacy and team efficacy, that are consistent with performance research outside the behavioural finance domain. For novices, teams may provide the confidence that boosts performance. The results of our experimental study also provide insights into the impact of trading activity on profits, the determinants of volatility in trading profit across participants, and the determinants of team trading profit. Because we assign subjects to roles we cannot provide any evidence on a membership effect in teams, but can give some insights into learning and effectiveness of newly formed teams.

The market is an electronic limit order based share-trading system similar to those in modern European and Australasian stock markets. ${ }^{1}$ Traders are given partial information about randomly drawn future dividend payments and are asked to trade two stocks over two periods. The task requires the processing of relatively complex information, inferences from the actions of other traders, and managing of market and limit orders and transactions. The computerized market interface and competition from a relatively large pool of traders create significant time pressures for participants while they are learning a new and complex task. Teams are expected to learn about and manage both strategic and tactical complexity with this task.

Section 2 and Section 3 describe the participants in the study and the trading system used to simulate the share market. Data are defined in Section 4 while results are reported in Section 5. Further, analysis of the groups and their trading behaviour appears in Section 6 with conclusions following in Section 7.

\footnotetext{
${ }^{1}$ Important differences from actual share trading systems include the structure of information flows as well as unlimited short sales and unlimited borrowing.
} 


\section{Participants}

Participants in the experiment were drawn from a first-year undergraduate finance course. All the participants had similar levels of previous experience with the trading software -- they attended a one-hour tutorial, required as part of their finance course, and completed an additional one-hour session of individual trading while taking part in an earlier experiment. While we do not assess their trading experience outside of class, most students are unlikely to have extensive trading experience. We assess their understanding of the trading process and valuation of the securities used in this market with a few simple queries (see Section 4.3); this evidence suggests limited trading and valuation skills.

A total of 54 students were either allocated to 17 two-person teams (34 subjects) or to act as individual traders (20 subjects). Stratified random allocation was used to allocate participants to the pool of individual traders or teams, with stratification based on gender. $^{2}$ Due to space limitations, teams were physically separated from individual traders using different rooms, although all participants knew that they were trading in the same electronic share trading market through a shared computer network. Having teams and individuals in separate computer laboratories made it easier to administer more detailed questionnaires to teams.

\section{Trading Task}

We used one of a suite of computerized trading cases, an investigation of market efficiency (RE1), described in O'Brien and Srivastava (1991) ${ }^{3}$ and supplied by OS Financial Trading Systems. This is an interactive computer case with one

\footnotetext{
${ }^{2}$ There were 17 males and 17 females allocated as team traders and 10 males and 10 females allocated as individual traders. Those who traded as teams were randomly assigned resulting in 4 teams of two males, five teams of two females and 8 teams of one male and one female.

${ }^{3}$ OS Financial Trading Systems, P.O. Box 11356 Pittsburgh. P.A. 15238, +1 8009679897 , email address: fts@ftsweb.com, web address: www.ftsweb.com.
} 
personal computer allocated to each individual participant or to each two-person team. Personal computers are linked to a common "market" computer that matches trades and reports basic summary information to participants. The market includes shares of two companies and there are no limits on short-selling shares or borrowing cash. While participants have access to up-to-date market information, including last-traded price, volume, and the bid-ask spread for each share, they are not endowed with full information about future dividends. Hence, share valuations are uncertain for each participant, but all participants jointly are told enough information to accurately compute all dividend flows (and hence share values) For simplicity we set the discount rate to zero and so share value is simply the sum of any future dividend payments.

The trading task takes approximately 45 minutes to complete, split into three trading sessions of approximately 15 minutes each. Each trading session consists of a 10-minute trial followed by a 5-minute period required to reset the case software and finalise incentive payments. Each 10-minute trial consists of two 5-minute trading periods. In period 1 the participants may predict dividends expected at the end of period 1 as well as the dividends expected at the end of period 2 to estimate the value of the share. They then trade in that period on the basis of the information that they have and what they can infer from watching the market record of the trading of others. The traders' computer screen includes the best bid and best ask price for each share as well as the valuation hints that are given to each individual (or team) about future dividends. In period 2 participants have the simpler task of predicting the dividend that will be paid at the end of this final period of the trial.

The two assets pay an uncertain dividend at the end of each of two consecutive 5-minute trading periods that make up a trial (share dividend payments are state 
dependent, where all states are equally likely, independent through time, and are described in more detail in Appendix 1). Each trader (or team) is given information about a state (and therefore a dividend payment) that will not occur. For example, in a particular 10-minute trial a participant might receive the information that the dividend in period 1 is not be the amount paid in state " $\mathrm{X}$ " and the dividend in period 2 is not the amount paid if state " $\mathrm{X}$ " was to occur for a second time. If this information is provided for the share labelled CRA then at the beginning of the trial the participant knows that CRA share will take a values of either $8,12,18,20,24,30,32,36$ or 42 , each with a probability of $1 / 9$ of occurring. ${ }^{4}$ The participant might compute a range of valuation metrics, for example the expected value of the share (24.67) as well as the maximum value of 42 and minimum value of 8 . On completion of the first trading period within the trial the first dividend is paid and so valuation focuses on the remaining dividend with a $1 / 3$ probability of receiving 8,12 or 18 (expected final dividend value of 12.67 with maximum value of 18 and minimum of 8 ). Thus, each participant receives incomplete information, and there are some differences in the information given to various traders. Sufficient information is made available to the market as a whole to identify the value of the share. As a consequence the case allows students to consider whether the market is efficient; i.e. whether the price reflects value even though each team has incomplete information about future cash flows.

Participants are allocated cash and securities (where the split between asset categories varies randomly across traders and trials) at the beginning of the task. While endowment effects are well known in the literature (Knetsch (1989); Kahneman, Knetsch, and Thaler (1991); Tversky and Kahneman (1991)) the variation

\footnotetext{
${ }^{4}$ Appendix 1 has a complete review of dividends and states for the two shares (ABC and CRA) traded in the market.
} 
in initial endowment is used to provide some incentive to trade, and over a number of trials different traders would see similar overall endowment realizations. The final value of all cash (from endowments, trading profits and dividends) from a particular trial (two consecutive five minute trading periods) is divided by 10,000 and reported on the screen as the participant's most recent "grade cash" (GC). These grade cash amounts are accumulated over the experiment to give the cumulative grade amount (TOT_GC). While the last grade cash amount indicates how well the participant has performed in the most recent trial, the cumulative grade keeps provides a running total of performance over the whole experiment. Aside from the initial endowments, cumulative grade cash increases with trading profit, hence we use it as our basic measure of trading effectiveness.

Cash incentives are paid to the participants with a fixed payment of $\$ 30.00$ to compensate for time and a further incentive payment of $\$ 10.00$ for each trial where grade cash from the trial exceeds a randomly selected benchmark number. The randomly selected benchmark number is accurate to four decimal places ranging from 0 to 1 inclusive and this number is selected immediately after each trial. ${ }^{5}$ This incentive scheme follows O'Brien and Srivastava (1991) who argue that it tends to encourage risk neutral, return maximising behaviour.

Once trading begins, participants indicate their wish to buy or sell securities by either entering a bid or ask price or choosing to accept existing ask or bid prices through the use of market orders. A depiction of the trading screen is provided in Figure 1. The key features of the task are apparent in this screen; a facility to enter bid and ask price and quantity or place market orders, disclosure of current bid and

\footnotetext{
${ }^{5}$ The random number is obtained by asking four different participants to select one of 10 cards using a set of cards with numbers 0 to 9 marked on the reverse side. Each participant chooses from the complete set of 10 cards (i.e. sampling with replacement). This gives a 4 digit random number drawn from a uniform distribution.
} 
ask prices, current holdings of each stock, grade cash, total grade cash, and private information about dividend payments.

\section{[Insert Figure 1 about here]}

\section{Data}

Trading profit, trading activity, confidence of traders and their understanding of the task are obtained either from the FTS program's audit trail (trading profit and trading activity) or from questionnaires administered before trading commenced (measures of confidence and understanding, see Appendix 2). A separate questionnaire was also given to team members upon completion of trading to assess their perceptions of team effectiveness (see Appendix 3).

\subsection{Final Cash Holdings and Trading Activity}

Table 1 contains descriptive statistics of a range of variables measuring trading performance and activity, and team characteristics. Final cash balances of each trader (or team) (TOT_GC) reflects initial cash holdings, dividends received from the shares, plus trading profits and losses at the end of each trial. From Panel A of Table 1 the average for team traders (12.83) is considerably larger than for the individual traders (-5.43) with an overall average across all teams and individuals of 2.96. While the team's final cash holdings are larger they are also considerably more variable - covering a much larger range with a higher standard deviation (68.21 for teams, compared to a standard deviation of 23.40 for the individuals).

[Insert Table 1 about here] 
Trading activity (defined as the total number of the bids, asks, clear bids, clear asks, buys, and sells during all trials (TOT_TRDS)) varies considerably, with individuals taking roughly double the number of actions (238) of teams (127) on average. There is considerable variation in activity for both individual and team traders, with one individual trader entering 1284 actions over a 30 -minute period. ${ }^{6}$

\subsection{Self Efficacy and Team Efficacy}

Confidence to perform a task (CONF_I), that is individual self-efficacy (Bandura (1999); Stajkovic and Luthans (1998)) and team efficacy (Gibson (2003); Gully, et al. (2002)), is a well-established motivational factor in determining the success of individuals performing well for a wide range of the tasks (Chan and $\mathrm{Lu}$ (2004); Christoph, Schoenfeld, and Tansky (1998); Hayashi et al. (2004); and Tan and Zhao (2003)) and we include a measure to capture individual efficacy. We administered a questionnaire to all participants prior to trading to ask how confident they are about five trading activities with responses coded over a 5-point Likert scale ranging from 1 (not at all confident) to 3 (moderately confident) to a maximum of 5 (totally confident).

The five activities are "pricing a share", "setting a bid", "setting an ask", "buying" and "selling". These account for parts a) to e) of the first section of the questionnaire in Appendix 2. These questions were answered before the task. Given the Cronbach alpha for the five questions is 0.92 we sum the five responses to provide a summary measure of participant confidence (CONF_I). For teams we use the

\footnotetext{
${ }^{6}$ Although this particular activity might appear frenzied, the audit trail shows that the trader seemed to follow a series of simple, yet rapidly enacted, trading rules that generated very small profits on each trade. While this approach worked well in the early part of the task for this trader, is appeared to be less effective in later trials.
} 
average of CONF_I across the two team members as a measure of team efficacy (for simplicity we report this average as CONF_I in our tables). ${ }^{7}$ From Table 1 we see little difference between the individual and team confidence measures, although the individual measures are more variable - to be expected given that the team measures are averages. So there appears to be little initial differences in confidence between teams and individuals at the start of the task.

\subsection{Understanding}

Participant understanding of the valuation of securities and the dividend process is expected to be a determinant of successful trading in a share market. We include a series of questions that address the participant's understanding of the key elements of valuation of the shares, dividend uncertainty, and the functioning of a limit order system. We measure participant understanding (UN_TOT_I) using questions that make up the latter part of the questionnaire in Appendix 2. The first question is about dividend information provided to participants and has four parts. The second and third questions focus on the ability of participants to identify bounds on share values. Question 4 analyzes the relation between first and second period dividends. Questions 5, 6 and 7 consider bid and ask prices and how market prices are set. Correct responses to these questions were assigned a value of 1 (incorrect responses were assigned a value of 0 ) and we sum these values to create a measure of understanding (UN_TOT_I). The Cronbach alpha for this measure is 0.67. We average the individual UN_TOT_I for the team understanding scores (for simplicity we also report this average as UN_TOT_I in our tables). ${ }^{8}$ Average understanding

\footnotetext{
${ }^{7}$ We repeated our analysis defining team efficacy as the self-efficacy of the team member that did most of the trading; the results were little changed.

8 As with the confidence measure, we repeat our team analysis using the answers from the team member that did most of the trading; results were consistent across these two measures.
} 
scores of 5.82 for team members and 6.65 for individual traders (questions correct out of 10) suggest that these are indeed novice traders.

Panel B of Table 1 contains correlations between various trader performance and trader characteristic measures. Aside from significant correlations between trading activity (TOT_TRDS) and our measure of trading profits (TOT_GC) most correlations are insignificant. The variables RTOT_GC (rank of grade cash) and LATOT_GC (logarithm of the absolute value of grade cash) are designed to address skewness and variability in grade cash, respectively, and are discussed in more detail below.

\subsection{Team Characteristics}

Appendix 3 details the team questionnaire completed at the end of the task and Panel C of Table 1 provides descriptive statistics for the key summary measures. The questionnaire consists of four parts, approach to the game, team effectiveness, impressions of other team members (co-worker perspective), and ranking of group tasks. Two participants in one team failed to complete this questionnaire and so we ignore this team in the following discussion.

Six questions are used to assess each team's approach to various tasks; setting a bid price (bidding), setting a ask price (asking), buying, selling and valuing the share (valuing). Questions in Appendix 3 that required the answer yes or no were coded with a 1 for yes and 0 for no. Question 1 asks for participant perceptions of their performance. The average of 3 suggests that the participants believed that they performed well at most of the tasks, although on closer analysis of individual responses a number of the participants do not believe that they performed well in 
valuing shares. Question 2 asks on how activities were split between the team members. More than half of the participants indicated that activities were not split between the participants in their group. Question 3 asks whether tasks are changed during trading (as distinct from split between the team members); responses to this question show that 7 of the 17 groups changed roles during trading. Further, the responses to question $3 \mathrm{a}$ show that there is considerable variation in the number of task changes; one change for two of the teams and two or more changes for the remaining 5 teams. Question 4 asks how frequently the teams discussed strategy and question 5 focuses on whether the teams discuss details of specific transactions, with mean responses of 5 and 4, respectively. It appears that all teams discuss both overall strategy and specific transactions, hence teams were relatively interactive and appear reasonably satisfied with their performance. We sum responses to all questions (excluding question $3 \mathrm{a}$ due to its narrow focus) to construct the summary measure GRP_ATT. The Cronbach alpha for this variable is 0.76 .

The second section of the team questionnaire consists of two questions about team effectiveness. In the first question the participants are asked about team communication and in the second question they are asked whether the group effectiveness improved over time (Cronbach alpha $=0.52)$. The responses are added together to create the variable, GRP_EFF.

The third section of the team questionnaire assesses co-worker impressions. There are 17 questions in this section. For a strongly performing group with good cohesion and a common goal we would expect to see numbers close to 1 for questions $8,13,16$ and numbers close to 5 for all other questions. Hence, the signs for the responses to questions 8,13 and 16 were reversed before summing across all 
questions to create a measure of co-worker impressions. The variable created by adding the signed response values is COWORK_I and has a Cronbach alpha of 0.86 .

The last sections of the group questionnaire consists of four parts, with 5 questions each, where the participants are asked to rate bidding, asking, buying, selling and valuing from easy (1) to hard (5) with respect to level difficulty for the team, level difficulty for the participant, whether the team is best at the task or whether the participant felt that they are best at the task. There was some variation in the responses to these questions, particularly for questions that ask the participant to self-assess their experience. The variable created by summing these responses is called TASK_DIF and has a Cronbach alpha of 0.66.

Panel D of Table 1 provides analysis of the gender and age of the participants in the electronic share trading task. While there are 54 participants taking part in the task one participant did not provide their personal details in their questionnaire sheet and so the statistics reported in panel D cover the remaining 53 participants. Average age is reported by group allocation and gender with no evidence of statistically significant differences in average age across either gender or trading classification (group trader or individual traders). Participants were allocated by trading classification to ensure an even distribution between male and female participants so as to minimise the possibility of gender bias in trading and this allocation is evident in the counts (reported in parentheses) appearing below the average age numbers in Panel D.

Correlation coefficients for measures of trading performance and team characteristics are reported in Panel E in Table 1. Co-worker impressions are related to a number of other team characteristics, while there appears to be relatively few significant relations between performance and team characteristics. 


\section{Analysis}

We begin by considering whether teams outperform individuals. The average individual scaled final cash holdings was a loss of 5.43 while teams had an average scaled final cash holding of 12.83 (Table 1). Because there is no limit on either borrowing or short-selling it is possible for significant variation in final cash holdings. The $t$-statistic for difference in scaled final cash holdings indicates that team outperformance is not statistically significant at the $5 \%$ level (Table 1). Further, there is no statistically significant difference between teams and individuals for any other variables reported in Panel A of Table 1. We control for gender effects through sample construction rather than use control variables.

Next we turn to the level of trading activity through time. The share trading task is made up of 3 trials of 10 minutes each, with every trial consisting of two 5 minute trading periods. To get a sense of the trading activity over a representative trading period we break each 5-minute trading period into 3010 -second sub-periods. The number of market instructions entered by participants in every 3010 -second subperiod (sub-periods 1 through 30 ) is averaged over the six trading periods that make up the share trading task and the result is plotted in Figure 2. Overall, participant activity tends to be somewhat lower early in a trading period. It builds in the first 100 seconds and levels out over the remaining 200 seconds of trading. We also plot market activity separately for group traders and individual traders. The 17 group traders generate 81 transactions per 10 second sub-period on average, while the 20 individual traders account for 150 transactions on average per 10 second sub-period. The difference in average activity per 10 second sub-period for individual traders relative to group traders is statistically significantly different at the $1 \%$ level, with the 
individuals accounting for almost twice the number of transactions per 10-second period. ${ }^{9}$ Thus, while there is little evidence of a difference in trading profit between groups and individuals it is clear from Figure 2 that individuals trade more frequently than do groups.

[Insert Figure 2 about here]

As further background, we consider price variability across the three trials that make up the share trading task. For $\mathrm{ABC}$ and CRA the average of transaction prices is computed across 10 second intervals for both of the 5-minute trading periods that make up each trial. Shares in the first period are entitled to two dividend payments, whereas shares in the second period have only one remaining dividend. Hence prices in the second period should be lower on average. Also, there is more precise information available to the traders about the value of each security in the second trading period of each trial, as the payment of the first dividend payment reduces uncertainty. Hence, we would also expect to see less variation in prices in the second trading period. The average traded price for each of the 3010 -second sub-periods is graphed in Figure 3. ${ }^{10}$ Because there is considerable average price volatility in the first 40 seconds of trading, the first four 10-second sub-periods are excluded from Figure 3. It should be noted that average prices for $\mathrm{ABC}$ generally exceed the average prices for CRA. Given that values are randomly allocated to the securities at the start of each trial some variation between the prices recorded for the two security prices is to be expected. Further, the prices traded in the first trading period within a trial tend to be lower than the prices traded in the second trading period for both of the

\footnotetext{
${ }^{9}$ The average difference is 106 transactions per 10 second period, with $\mathrm{t}$ statistic $=9.45$.

${ }^{10}$ Security 1 is ABC and security 2 is CRA.
} 
securities, with the difference being statistically significant at the $1 \%$ level. ${ }^{11}$ This is somewhat surprising as shares are (weakly) more valuable in the first period. There is little evidence of trading patterns over the 5-minute trading sessions like the "Ushaped" trading pattern often noted in the microstructure literature.

Given these patterns in price and activity we want to learn more about subjects' understanding of the trading and valuation details of the task. Responses to the questionnaire (see Appendix 2) provide an opportunity to assess the level of participant knowledge about share trading and share valuation in this setting. The questionnaire was completed by participants at both the beginning and the end of the share trading task and it was completed regardless of whether participants traded on their own or as part of a group. The best response was 10 correct answers out of 10 questions, with the worst response containing no correct answers at all (recorded in a questionnaire completed at the end of the trading task). Averages of 6 correct responses was recorded across all participants with a standard deviation of 2.3 for the questionnaire administered at the start of trading and 2.5 for the questionnaire completed at the end of trading. To assess whether there might be influences from variation in the level of understanding, t-tests were conducted over the sum of the number of correct responses to the 10 questions that dealt with participant understanding. There was no statistically significant difference between average understanding for team traders versus individual traders in the initial questionnaire (5.82 correct responses for team traders and 6.65 correct responses for individual traders). Yet, individual traders show a greater level of understanding (6.75 correct responses on average) than team traders (5.50 correct responses on average) in the questionnaire given when trading was complete (this difference is significant at the

\footnotetext{
${ }^{11}$ The average difference for $\mathrm{ABC}$ is 3.15 with a t statistic of 4.76 and the average difference for CRA is 4.43 with a t statistic of 6.92 .
} 
$5 \%$ level). While the individual trader questionnaire results seemed to suggest greater learning, these are fairly low average scores and are consistent with participants being new to these specialized tasks.

\subsection{Trading profit}

There is considerable variation in scaled final cash balances across participants, whether trading as individuals or as teams, yet the univariate analysis suggests that team and individual differences are not particularly notable. We use multivariate regression to analyse the impact of teams. We explain scaled final cash holdings using confidence, understanding, and trading activity measures as well as whether a trader was a team.

We regress scaled cash final balances (TOT_GC) on participant confidence (self efficacy and team efficacy as is relevant), understanding (self and team understanding as is relevant), trading activity and a group dummy variable to capture whether it was a team or individual trader. We also include interaction terms between the team dummy variable and confidence, understanding and trading activity.

$$
T O T_{-} G C_{i}=\left[\begin{array}{l}
\alpha_{0}+\alpha_{1} C O N F_{-} I_{i}+\alpha_{2} U N_{-} T O T_{-} I_{i} \\
+\alpha_{3} T O T_{-} T R D S_{i}+\alpha_{4} G R P_{-} T R D R_{i}+\alpha_{5} G X C O N F_{-} I_{i} \\
+\alpha_{6} G X U N_{-} T O T_{-} I_{i}+\alpha_{7} G X T R D_{i}+\varepsilon_{i}
\end{array}\right.
$$

where TOT_GC $C_{i}=$ trading profit for trader $i$,

$C O N F_{-} I_{i}=$ self-efficacy or confidence for trader $i$,

$U N_{-} T O T \_I_{i}=$ participant understanding for trader $i$,

$T O T \_T R D S_{i}=$ trading activity for trader $i$,

$G R P_{-} T R D R_{i}=$ team trader dummy variable with value of 1 if a team and a value 0 otherwise for trader $i$.

GXCONF_I, GXUN_TOT_I and GXTRD = interaction terms between the team trader dummy variable and the other explanatory variables 
This exploratory analysis suggests that only one variable, TOT_TRDS, shows much promise as an explanatory variable (the probability associated with an $F$-test for exclusion of all but the total activity variable was 0.831 ). If we were to restrict the model to only consider trader activity we would have:

$$
T O T_{-} G C_{i}=\alpha_{0}+\alpha_{1} T O T_{-} T R D S_{i}+\varepsilon_{i}
$$

As reported in Panel A of Table 3 there is a statistically significant negative relation between the trading activity and final scaled cash balances. The more an individual or team buys, sells, bids, or asks (or cancels limit orders) the lower their eventual cash holdings. While the regression is statistically significant and the majority of the diagnostic statistics suggest a well-behaved model, its residuals are not normally distributed. On checking the data there are a number of extremely large positive and negative final cash balances.

[Insert Table 2 about here]

To reduce the impact of outliers without losing observations, the final scaled cash balances are ranked and these ranks are substituted as the dependent variable. This specification follows equation (1) with TOT_GC being replaced by ranks (RTOT_GC). Exploratory analysis suggests that two variables, CONF_I and TOT_TRDS, are of potential interest. In Panel B of Table 2 we report the regression with both variables included, with a form of:

$$
R T O T_{-} G C_{i}=\alpha_{0}+\alpha_{1} C O N F_{-} I_{i}+\alpha_{1} T O T_{-} T R D S_{i}+\varepsilon_{i}
$$


where RTOT_GC $C_{i}=$ rank of the scaled final cash balance of trader $i$. The low $t$ statistics suggest multicollinearity; however the correlation between these explanatory variables $(-0.234)$ is not statistically significant. Nevertheless, this regression is better behaved than equation (2), with no rejection of the assumption of normally distributed residuals.

It appears that there may be a positive relation between confidence and trading profit and a negative relation between the trading activity and trading profit. Thus, while trading activity is still instrumental in determining trading effectiveness, the positive coefficient for CONF_I suggests that confidence (self and team efficacy) is positively related to trading outcomes. The level of understanding does not appear to have had much impact, nor is there evidence to suggest that teams generate significantly more profits than individuals.

It is possible that gender has an impact on these results. We re-run the analysis with a gender dummy variable included for individual trader analysis, as well as group gender dummy variables (all male group or all female group) for analysis of group behaviour. While there is no evidence of a gender effect for the individual traders there is some evidence that all male groups statistically significantly higher trading profits than mixed gender groups, while all female groups are not statistically significantly different from the mixed gender groups in their trading profits. Given the small sample size for these analyses (4 all male groups out of 17 groups) it is difficult to draw any conclusion from this result. Indeed when equation (3) is estimated using these same gender tests the difference in performance to all male groups is no longer detectable.

\subsection{Variability in trading profit}


While the previous section suggests that there is little evidence of teams being more profitable on average, it is possible that teams generate more consistent trading profits (see Heaney, et al. (2005)). We use as our measure of trading profit volatility the natural logarithm of the absolute value of the scaled final cash holdings (LATOT_GC). Following the structure of expression (1) we regress this volatility measure on participant confidence, understanding, trading activity, a team dummy, and interaction terms between the group dummy variable and participant confidence, understanding and trading activity:

$$
L A T O T_{-} G C_{i}=\left[\begin{array}{l}
\alpha_{0}+\alpha_{1} C O N F_{-} I_{i}+\alpha_{2} U N_{-} T O T_{-} I_{i} \\
+\alpha_{3} T O T_{-} T R D S_{i}+\alpha_{4} G R P_{-} T R D R_{i}+\alpha_{5} G X C O N F_{-} I_{i} \\
+\alpha_{6} G X U N_{-} T O T_{-} I_{i}+\alpha_{7} G X T R D_{i}+\varepsilon_{i}
\end{array}\right.
$$

where $L A T O T_{-} G C_{i}=$ is a measure of trading profit volatility for trader $i$,

To begin, the full model was estimated with the group dummy and all interaction terms. This exploratory analysis found that $t$-statistics on two of the interaction terms and the group dummy variable were small and an $F$-test for exclusion of these variables was conducted with a probability of 0.953 . An updated model was re-estimated without these variables and is reported in Table 3.

$$
L A T O T_{-} G C_{i}=\left[\begin{array}{l}
\alpha_{0}+\alpha_{1} C O N F_{-} I_{i}+\alpha_{2} U N_{-} T O T_{-} I_{i} \\
+\alpha_{3} T O T_{-} T R D S_{i}+\alpha_{4} G X T R D_{i}+\varepsilon_{i}
\end{array}\right.
$$


The $F$-test indicates a statistically significant model and the Jarque-Bera test for normal distribution, White's test for heteroscedasticity and the Ramsey RESET tests for functional form problems suggest that the model fits the data reasonably well.

\section{[Insert Table 3 about here]}

The two coefficients based on trading activity, TOT_TRDS and GXTRD, are both statistically significant and positive. The TOT_TRDS coefficient shows that the individual trading activity is positively correlated with the volatility of trading profit and the interaction term, GXTRD, suggests that this positive relation is stronger for teams than for individuals. The coefficient on UN_TOT_I is positive and statistically significant at the 5\% level. The coefficient for confidence, or self-efficacy, (CONF_I) is positive and statistically significant at the $10 \%$ level, suggesting that self-efficacy is positively related with cross-sectional variation in trading profit. It appears that knowledgeable, confident participants who trade heavily generate more volatile trading profits. Perhaps these results are not particularly surprising given our sample of novice traders taking part in a complex share market trading task.

There is some statistical support for the argument that those participants who trade more and have a better understanding of the task have more volatile trading profits. There is also evidence that more confident traders have more volatile trading profits and that team trading profit volatility is more sensitive to trading activity than individual trading profit volatility.

\section{Teams}


From Table 1 we know that teams are responsible for both the best and the worst trading performance in our experiment. While average confidence, understanding, and trading activity are fairly similar across teams and individuals, the standard deviation of trading activity is much lower for teams than for individuals. Thus teams appear to be much more measured in their trading behaviour, at least in terms of trading activity.

We investigate team performance in more detail using our measures of team attitude to trading, team effectiveness, co-worker impressions, and task difficulty. The team questionnaire was completed at the end of trading and contains the views of these traders with some experience and knowing their profitability (although they were not aware of the profitability of the other traders).

We begin by using equation (1), using the rank of TOT_GC (RTOT_GC). Our exploratory analysis suggests that trading activity, team attitude, and perceived task difficulty are related to trading effectiveness (although individual statistical significance of the variables is sensitive to variable inclusion because of multicollinearity and a small sample size (See Table 4, Panel A)):

$$
R T O T_{-} G C_{i}=\alpha_{0}+\alpha_{1} T O T_{-} T R D S_{i}+\alpha_{2} G R P_{-} A T T_{i}+\alpha_{31} T A S K_{-} D I F_{i}+\varepsilon_{i}
$$

where GRP_ATT $T_{i}=$ attitude to trading for team $i$,

$T A S K_{-} D I F_{i}=$ individual perceptions about task difficulty for the team and for the individual of team $i$,

\section{[Insert Table 4 about here]}

These results provide some insight into what determines trading profit for the 16 teams. Consistent with the full sample analysis, there is a negative relation between trading profit and trading activity. Both group attitude and task difficulty 
appear to have an impact on trading profit, with increased perceived difficulty associated with lower trading profits and stronger group attitude to the task associated with higher trading profits. ${ }^{12}$

We relate our team descriptive variables to trading activity, because it appears to be an important determinant of final scaled cash holdings:

$$
T O T_{-} T R D_{i}=\left[\begin{array}{l}
\alpha_{0}+\alpha_{1} G R P_{-} A T T_{i}+\alpha_{2} G R P_{-} E F F_{i} \\
+\alpha_{3} C O W O R K_{-} I_{i}+\alpha_{4} T A S K_{-} D I F_{i}+\varepsilon_{i}
\end{array}\right.
$$

Our exploratory analysis suggests the following simplified model (see Table 4, Panel B):

$$
\text { TOT_TRD }{ }_{i}=\alpha_{0}+\alpha_{1} C O W O R K_{-} I_{i}+\varepsilon_{i}
$$

The coefficient on the co-worker impressions is negative which suggests a stronger impression of co-worker abilities results in less trading. All teams reported that they discussed both strategy and details of trading but it appears that in teams where individuals had a fairly high degree of respect for each other, trading proceeded more slowly.

\section{Conclusion}

We find little evidence of significant differences in trading profit between team and individual traders. However, we find that the variability of trading profit is more sensitive to trading activity for teams than for individuals.

12 Cross-sectional regression analysis of variation in trading profit did not yield significant relations (while parameter signs were generally consistent with the full sample analysis) so results are not reported. 
Closer analysis of teams suggests that trading activity is an important determinant of profits and it is apparent that group attitude and perceived task difficulty are related to team performance. Finally, co-worker impressions are negatively correlated with trading activity, suggesting that these teams may be more deliberative in their actions.

Further research is needed to explore the mediating processes though which novices, working alone or in teams, learn and then use this knowledge when trading. Experimental studies, like the one reported here, can provide a valid basis for understanding the dynamics of the trading of novices (Wood, Goodman, Beckmann and Cook (2008)). This knowledge can then form a basis for the design of skill development and training programs. 


\section{References}

Adams, R., and Ferreira, D., 2009, Moderation in Groups: Evidence from Betting on Ice Break-ups in Alaska. Working paper, University of Queensland and ECGI.

Bandura, A., 1978, The Self-System in Reciprocal Determinism, American Psychologist, 33, 344-358.

Bandura, A. 1997, Self-Efficacy: The Exercise of Control. New York: Freeman.

Barber, B.M., Heath, C. and Odean, T., 2003, Good Reasons Sell: Reason-Based Choice Among Group and Individual Investors in the Stock Market, Management Science, 49, 1636-1652.

Barber, B.M. and Odean, T., 2000a, Trading is Hazardous to Your Trading Profit: The Common Stock Investment Performance of Individual Investors, The Journal of Finance, 55, 773-806.

Barber, B.M. and Odean, T., 2000b, Too Many Cooks Spoil the Profits: The Performance of Investment Clubs, Financial Analysts Journal, 56, 17-25.

Byrne, J.A., 1993, The Virtual Corporation, Business Week, Issue 3304, 98-103.

Cooper, D.J. and J.H. Kagel, 2005, Are Two Heads Better Than One? Team versus Individual Play in Signalling Games, The American Economic Review, 95, 477-509.

Chan, S.-C., and Lu, M.-T., 2004, Understanding Internet Banking Adoption and Use Behavior: A Hong Kong Perspective, Journal of Global Information Management, 12, 21-43.

Christoph, R.T., Schoenfeld, G.A. Jr. and Tansky, J.W., 1998, Overcoming Barriers to Training Utilising Technology: The Influence of Self-Efficacy Factors on Multimedia-Based Training Receptiveness, Human Resource Development Quarterly, 9, 25-38.

Gibson, B.C., 1999, Do They Do What They Believe They Can? Group Efficacy and Group Effectiveness Across Tasks and Cultures. Academy of Management Journal, $42,138-152$.

Gibson, C.B., 2003, The Efficacy Advantage: Factors Related to the Formation of Group Efficacy. Journal of Applied Social Psychology, 33, 2153-2186.

Gully, S.M., Incalcaterra, K.A., Joshi, A., and Beaubien, J.M., 2002, A Meta-Analysis of Team-Efficacy, Potency, and Performance: Interdependence and Level of Analysis as Moderators of Observed Relationships. Journal of Applied Psychology, 87(5), 819832. 
Hayashi, A., Chen, C., Ryan, T. and Wu J., 2004, The Role of Social Presence and Moderating Role of Computer Self-Efficacy in Predicting the Continuance Usage of E-Learning Systems, Journal of Information Systems Education, 15, 139-154.

Heaney, R.A., Foster, F.D., Gregor, S., O’Neill, T., and Wood, R.E., 2007, "Volatility in Returns from Trading", The Journal of Behavioral Finance, 8, 35-42.

Jehn, K.A., Chadwick, C. and Thatcher, S.M.B, 1997, To agree or not to agree: The effects of value congruence, individual demographic dissimilarity, and conflict on workgroup outcomes, The International Journal of Conflict Management, 8, 287-305.

Kahneman, D., Knetsch, J.L. and Thaler, R.H, 1991, The Endowment Effect, Loss Aversion, and Status Quo Bias, Journal of Economic Perspectives, 5, 193-206.

Knetsch, J.L., 1989, The Endowment Effect and Evidence of Nonreversible Indifference Curves, The American Economic Review, 79, 1277-1284.

Kocher, M.G. and Sutter, M., 2005, The Decision Maker Matter: Individual versus Group Behaviour in Experimental Beauty-Contest Games, The Economic Journal, $115,200-223$.

O'Brien, J. and S. Srivastava, 1991, Dynamic Stock Markets With Multiple Assets: An Experimental Analysis, The Journal of Finance, 46, 1811-1838.

Odean, T., 1999, Do Investors Trade Too Much? The American Economic Review, 89, 1279-1298.

Prather, L.J., and Middleton, K.L., 2002, Are N+1 Heads Better than One? The Case of Mutual Fund Managers, Journal of Economic Behavior and Organization, 47, 103120.

Prather, L.J., Middleton, K.L., and Cusack, A.J., 2001, Are N+1 Heads Better than One? The Timing and Selectivity of Australian-Managed Investment Funds, PacificBasin Finance Journal, 9, 379-400.

Stajkovic, A.D., and Luthans, F., 1998. Self-Efficacy and Work-Related Performance: A Meta-Analysis. Psychological Bulletin, 24, 240-261

Tan, H.H. and Zhao, B., 2003, Individual-and Perceived Contextual-Level Antecedents of Individual Technical Information Inquiry in Organizations, Journal of Psychology, 137, 597-621.

Tversky, A. and Kahneman, D., 1991, Loss aversion in riskless choice: A referencedependent model, Quarterly Journal of Economics, 106, 1039-61.

Wood, R.E. and Bandura, A., 1989, "Social Cognitive Theory of Organizational Management" Academy of Management Review, 14, 361-384 
Wood, R.E, Goodman, J.S., Beckmann, N, and Cook, A. I., 2008 "Mediation Testing in Management Research: A Review and Proposals" Organizational Research Methods, 11 (2), 270-295. 


\section{Appendix 1 - Dividend Determination}

There are two trading periods with dividends paid at the end of the each period. Participants do not have full information concerning the dividend payments but instead each participant is given partial information - one possible state is ruled out in each period.

The following table describes the equally likely events affecting each firm, and the dividends associated with each state in the first period. State realizations are independent across firms and through time.

\begin{tabular}{ccc}
\hline ABC & & Dividend \\
\hline Event X & Poor economic conditions, labour strike & 0 \\
Event Y & Poor economic conditions, no strike & 12 \\
Event Z & Fair economic conditions, good labour relations & 24 \\
\hline CRA & & Dividend \\
\hline Event W & Poor economic conditions, labour strike & 0 \\
Event X & Poor economic conditions, no strike & 12 \\
Event Y & Fair economic conditions, no strike & 12 \\
Event Z & Fair economic conditions, good labour relations & 24 \\
\hline
\end{tabular}

The dividends paid at the end of period 2 depend on both the period 1 state and the period 2 state as follows:

\section{Firm ABC}

\begin{tabular}{cccc}
\hline Period 1 Event & \multicolumn{3}{c}{ Period 2 Event } \\
\hline Per2 Col/Per 1 Row & $\mathrm{X}$ & $\mathrm{Y}$ & $\mathrm{Z}$ \\
$\mathrm{X}$ & 0,0 & 0,0 & 0,12 \\
$\mathrm{Y}$ & 12,0 & 12,12 & 12,24 \\
$\mathrm{Z}$ & 24,12 & 24,12 & 24,24 \\
\hline
\end{tabular}

\section{Firm CRA}

\begin{tabular}{ccccc}
\hline Period 1 Event & \multicolumn{4}{c}{ Period 2 Event } \\
\hline Per 2 Col/Per 1 Row & $\mathrm{W}$ & $\mathrm{X}$ & $\mathrm{Y}$ & $\mathrm{Z}$ \\
W & 0,8 & 0,8 & 0,12 & 0,18 \\
X & 12,8 & 12,8 & 12,12 & 12,18 \\
Y & 12,8 & 12,8 & 12,12 & 12,18 \\
Z & 24,8 & 24,8 & 24,12 & 24,18 \\
\hline
\end{tabular}




\section{Examples}

Suppose the realized events for $A B C$ are:

i. $\quad \mathrm{Y}$ in period 1 and $\mathrm{Y}$ in period 2. At the end of period $1 \mathrm{ABC}$ pays a dividend equal to 12 and at the end of period 2 it pays 12 (see cell row Y, column $\mathrm{Y}$ in the $\mathrm{ABC}$ table above (12,12 for period 1 and period 2 respectively)

ii. $\quad \mathrm{Z}$ in period 1 and $\mathrm{X}$ in period 2. At the end of period $1 \mathrm{ABC}$ pays a dividend equal to 24 and at the end of period 2 it pays 12 (see cell row $\mathrm{Z}$, column $\mathrm{X}$ in the $\mathrm{ABC}$ table above $(24,12$ for period 1 and period 2 respectively)

Suppose the realized events for CRA are:

i. $\quad \mathrm{W}$ in period 1 and $\mathrm{Z}$ in period 2. At the end of period 1 CRA pays a dividend equal to 0 and at the end of period 2 it pays 18 (see cell row $\mathrm{W}$, column $\mathrm{Z}$ above $(0,18$ for period 1 and period 2 respectively)

ii. $\quad Z$ in period 1 and $X$ in period 2. At the end of period 1 CRA pays a dividend equal to 24 and at the end of period 2 it pays 8 (see cell row Z, column $\mathrm{X}$ above ( 24,8 for period 1 and period 2 respectively) 


\section{Appendix 2 - Self-Efficacy and Understanding Questionnaire}

\section{Confidence in trading with the FTS trading system game (Self Efficacy)}

Listed below are activities that could be completed during financial trading with the FTS system. Please indicate how confident you feel in performing each activity by circling one number. If you are not sure of what to do or what the question refers to, please circle the " 0 ".

a) Pricing a share

\begin{tabular}{c}
\hline Not sure \\
b) Setting a bid \\
0 \\
\hline Not sure \\
c) Setting an as \\
0 \\
\hline Not sure \\
d) Buying \\
0 \\
\hline Not sure \\
e) Selling \\
0 \\
\hline Not sure
\end{tabular}

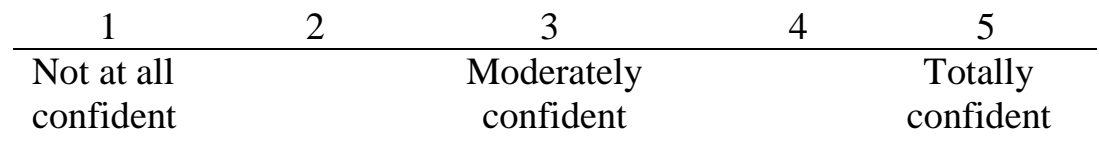

\begin{tabular}{|c|c|c|c|c|}
\hline 1 & 2 & 3 & 4 & 5 \\
\hline $\begin{array}{l}\text { Not at all } \\
\text { confident }\end{array}$ & & $\begin{array}{l}\text { Moderately } \\
\text { confident }\end{array}$ & & $\begin{array}{c}\text { Totally } \\
\text { confident }\end{array}$ \\
\hline
\end{tabular}

\begin{tabular}{ccccc}
1 & 2 & 3 & 4 & 5 \\
\hline $\begin{array}{l}\text { Not at all } \\
\text { confident }\end{array}$ & $\begin{array}{c}\text { Moderately } \\
\text { confident }\end{array}$ & & $\begin{array}{c}\text { Totally } \\
\text { confident }\end{array}$
\end{tabular}

\begin{tabular}{|c|c|c|c|c|}
\hline 1 & 2 & 3 & 4 & 5 \\
\hline $\begin{array}{l}\text { Not at all } \\
\text { confident }\end{array}$ & & $\begin{array}{c}\text { Moderately } \\
\text { confident }\end{array}$ & & $\begin{array}{c}\text { Totally } \\
\text { confident }\end{array}$ \\
\hline
\end{tabular}

\begin{tabular}{|c|c|c|c|c|}
\hline 1 & 2 & 3 & 4 & 5 \\
\hline $\begin{array}{l}\text { Not at all } \\
\text { confident }\end{array}$ & & $\begin{array}{c}\text { Moderately } \\
\text { confident }\end{array}$ & & $\begin{array}{c}\text { Totally } \\
\text { confident }\end{array}$ \\
\hline
\end{tabular}




\section{FTS Stock Valuation}

Please answer the following questions about stocks ABC. You may need to read the "Dividend Determination Sheet" to answer these questions.

1. For stock $A B C$, if it is event " $Y$ " in the first period and event " $Z$ " in the second period:

a) What is the dividend paid in the first period?

b) What is the dividend paid in the second period?

c) What is the value of the share in the first period?

d) What is the value of the share in the second period?

2. What is the minimum value that $\mathrm{ABC}$ can take in the first period?

3. What is the maximum value that $\mathrm{ABC}$ can take in the second period?

4. If you know "not y in period 1" for stock $A B C$ what are the possible dividends that could be paid in period 1 ?

5. If the current bid and ask prices / depths are $\$ 22$ / 200 and $\$ 26$ / 300, respectively and you place a "buy" order for 200 shares, what price will you pay for the shares?

$\$$ per share

6. If the current bid and ask prices / depths are $\$ 22$ / 200 and $\$ 26 / 300$, respectively and you place an "ask" at a price / depth of $\$ 25 / 250$, will your new ask be used if the next action in the market is a buy order for 100 shares?

$\square$ Yes $\quad \square$ No

7. If the current bid and ask prices / depths are $\$ 22$ / 200 and $\$ 26$ / 300, respectively and you place an "ask" at a price / depth of $\$ 27 / 250$, will your new ask be used if the next action in the market is a buy order for 100 shares?

$\square$ Yes $\quad \square$ No 


\section{Appendix 3 - Team Questionnaire}

\section{How your group approached the game}

In this section we ask you how your group approached trading. Please write the letter required in each box below the task.

\begin{tabular}{|l|l|l|l|l|l|}
\hline Attitude to Trading & Bidding & Asking & Buying & Selling & Valuing \\
\hline $\begin{array}{l}\text { 1. For each task, do you think you performed well } \\
\text { at it? } \\
\text { (Y = yes, } \mathrm{N}=\text { no) }\end{array}$ & & & & & \\
\hline $\begin{array}{l}\text { 2. How were the tasks split (ie. which person did } \\
\text { what)? } \mathrm{Y}=\text { you, } \mathrm{P}=\text { partner, } \mathrm{B}=\text { both) }\end{array}$ & & & & & \\
\hline $\begin{array}{l}\text { 3. Did you change who did which task? } \\
\text { (Y= yes, } \mathrm{N}=\text { no) }\end{array}$ & & & & & \\
\hline $\begin{array}{l}\text { 3a. If you changed tasks, how often did you } \\
\text { change? } \\
\text { (1 - once, } 2 \text { - twice, ..., } \mathrm{M}=\text { many) }\end{array}$ & & & & & \\
\hline $\begin{array}{l}\text { 4. Did you discuss trading strategies with your } \\
\text { partner often? }(\mathrm{Y}=\text { yes, } \mathrm{N}=\text { no) }\end{array}$ & & & & & \\
\hline $\begin{array}{l}\text { 5. Did you discuss transaction details with your } \\
\text { team member often? }(\mathrm{Y}=\text { yes, } \mathrm{N}=\text { no) }\end{array}$ & & & & & \\
\hline
\end{tabular}

\section{Team effectiveness}

\begin{tabular}{|l|l|}
\hline Question & Response \\
\hline Was your team effective at communicating? $\quad(\mathrm{Y}=$ yes, $\mathrm{N}=$ no $)$ & \\
\hline Did your team's effectiveness improve over time? $\quad(\mathrm{Y}=$ yes, $\mathrm{N}=$ no $)$ & \\
\hline
\end{tabular}




\section{Team impressions}

\section{INSTRUCTIONS:}

Using the following scale to record your impressions of your trading partner. Write a number from 1 to 5 in each box in the grid:

$1=$ doesn't describe trading partner at all

$2=$ doesn't describe trading partner very well

$3=$ describes trading partner somewhat

$4=$ describes trading partner well

$5=$ describes trading partner very well

\begin{tabular}{|ll|l|}
\hline Impression & Number \\
\hline $1 . \quad$ Had high performance expectations for the task. & \\
\hline $2 . \quad$ Raised issues regarding how well we worked together. & \\
\hline $3 . \quad$ Assumed a leadership role in the task. & \\
\hline $4 . \quad$ Was well prepared for the task. & \\
\hline $5 . \quad$ Is someone I enjoy working with. & \\
\hline $6 . \quad \begin{array}{l}\text { Tries to get us back on track when we wandered off the } \\
\text { task. }\end{array}$ & \\
\hline $7 . \quad$ Pulled his/her weight in the completion of tasks. & \\
\hline $8 . \quad$ Only participated in group activity when asked. & \\
\hline 9. & Stimulated me to continue working when we lost focus. & \\
\hline $10 . \quad$ Tried to resolve conflicts that arose. & \\
\hline $11 . \quad$ Was concerned about the quality of our performance. & \\
\hline $12 . \quad$ Is someone I trust. & \\
\hline $13 . \quad$ Took the work on the task too lightly. & \\
\hline $14 . \quad$ Helped us to maintain focus. & \\
\hline $15 . \quad$ Encouraged me to talk and listened to me. & \\
\hline $16 . \quad$ Did not perform up to the level I expected. & \\
\hline 17. & Is someone I would like to work with in the future. & \\
\hline
\end{tabular}




\section{Ranking of the group tasks}

Listed below some questions concerning your views on how your team performed during financial trading with the FTS system. Please indicate your ranking by circling one number. If you are not sure of what to do or what the question refers to, please write a " 0 ".

a) For your team, rank order the tasks by difficulty

\begin{tabular}{|l|l|}
\hline Task & Team rank (1 - easy to 5 - hard) \\
\hline Bidding & \\
\hline Asking & \\
\hline Buying & \\
\hline Selling & \\
\hline Valuing & \\
\hline
\end{tabular}

b) For yourself, rank order the tasks by difficulty

\begin{tabular}{|l|l|}
\hline Task & Your rank $(1-$ easy to 5 - hard $)$ \\
\hline Bidding & \\
\hline Asking & \\
\hline Buying & \\
\hline Selling & \\
\hline Valuing & \\
\hline
\end{tabular}

c) For your team, rank order the tasks that your team was best at

\begin{tabular}{|l|l|}
\hline Task & Team rank (1 - best to 5 - worst $)$ \\
\hline Bidding & \\
\hline Asking & \\
\hline Buying & \\
\hline Selling & \\
\hline Valuing & \\
\hline
\end{tabular}

d) For yourself, rank order the tasks that you were best at

\begin{tabular}{|l|l|}
\hline Task & Your rank (1 - best to 5 - worst $)$ \\
\hline Bidding & \\
\hline Asking & \\
\hline Buying & \\
\hline Selling & \\
\hline Valuing & \\
\hline
\end{tabular}


Figure 1 - The Trading Screen

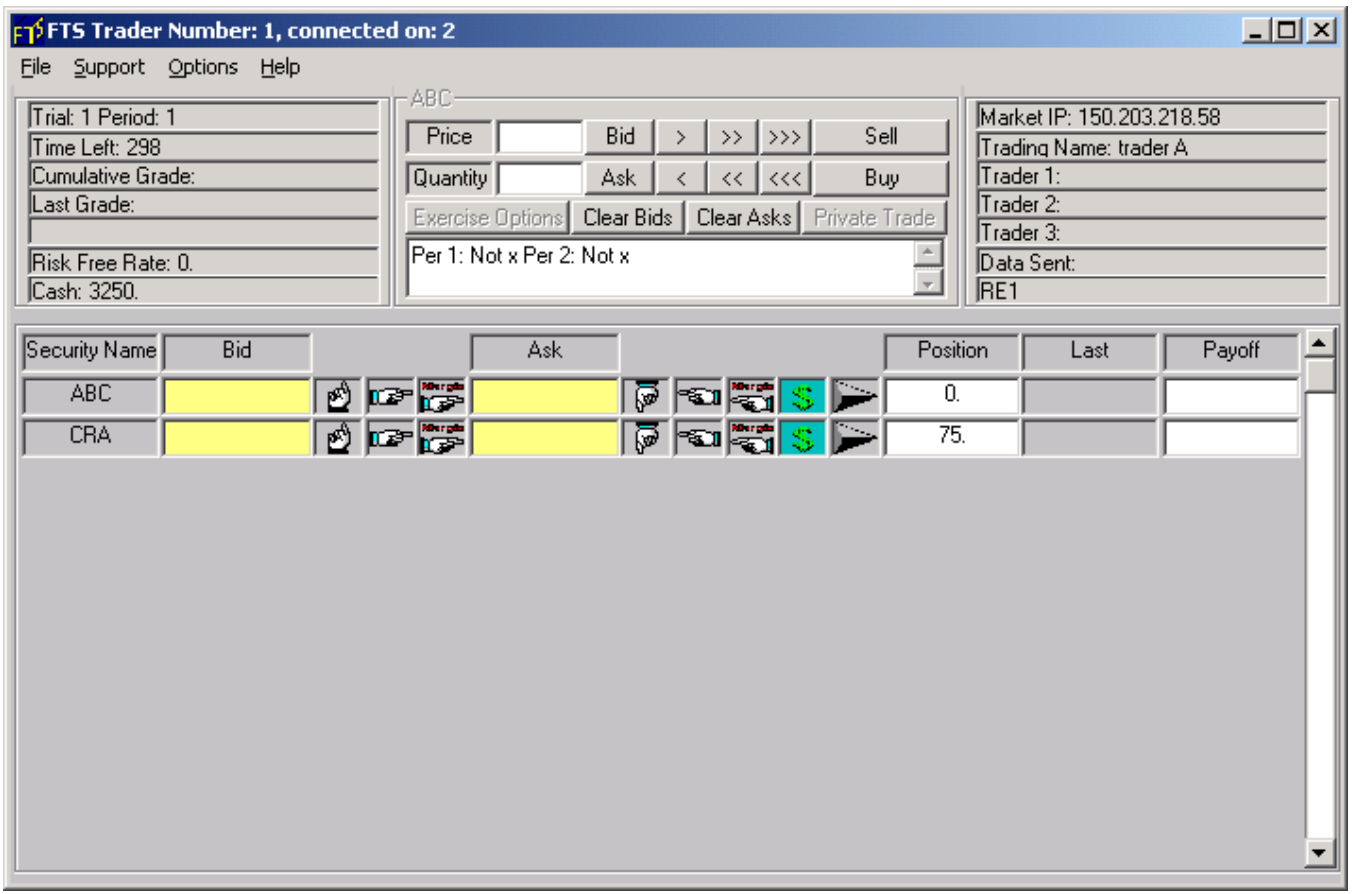

This is an example of the screen that the participants see while trading. There are essentially four sections to the screen located in the top right section, the top left section, the top middle section and the section in the middle of the screen.

i. $\quad$ The top left section identifies the particular trading periods, time remaining in the present trading period, measures of trading profit (cumulative grade and last grade), the risk free rate and level of cash currently on hand. Last grade is a measure of initial cash endowments, any dividends paid, and any trading profit earned in the last trial. Cumulative grade is the last grade value summed over all completed trials. The risk free rate is set to zero for simplicity.

ii. The top right section provides static participant identification information.

iii. The top centre section is where trades and quotes are entered. For a buy or sell at market, the participant enters the quantity of shares and selects Buy or Sell. For a limit order the participant enters the limit quantity and price and then selects Bid or Ask. There are also a facility to clear current bids and asks. Private information about security payoffs in each period is included in the white box in this section.

iv. The section in the middle of the screen provides current best bid and ask prices and depths as well as the participant's current share position, last traded price and most recent dividend for each share. 
Figure 2 - Average Market Activity across 5 Minute Trading Periods

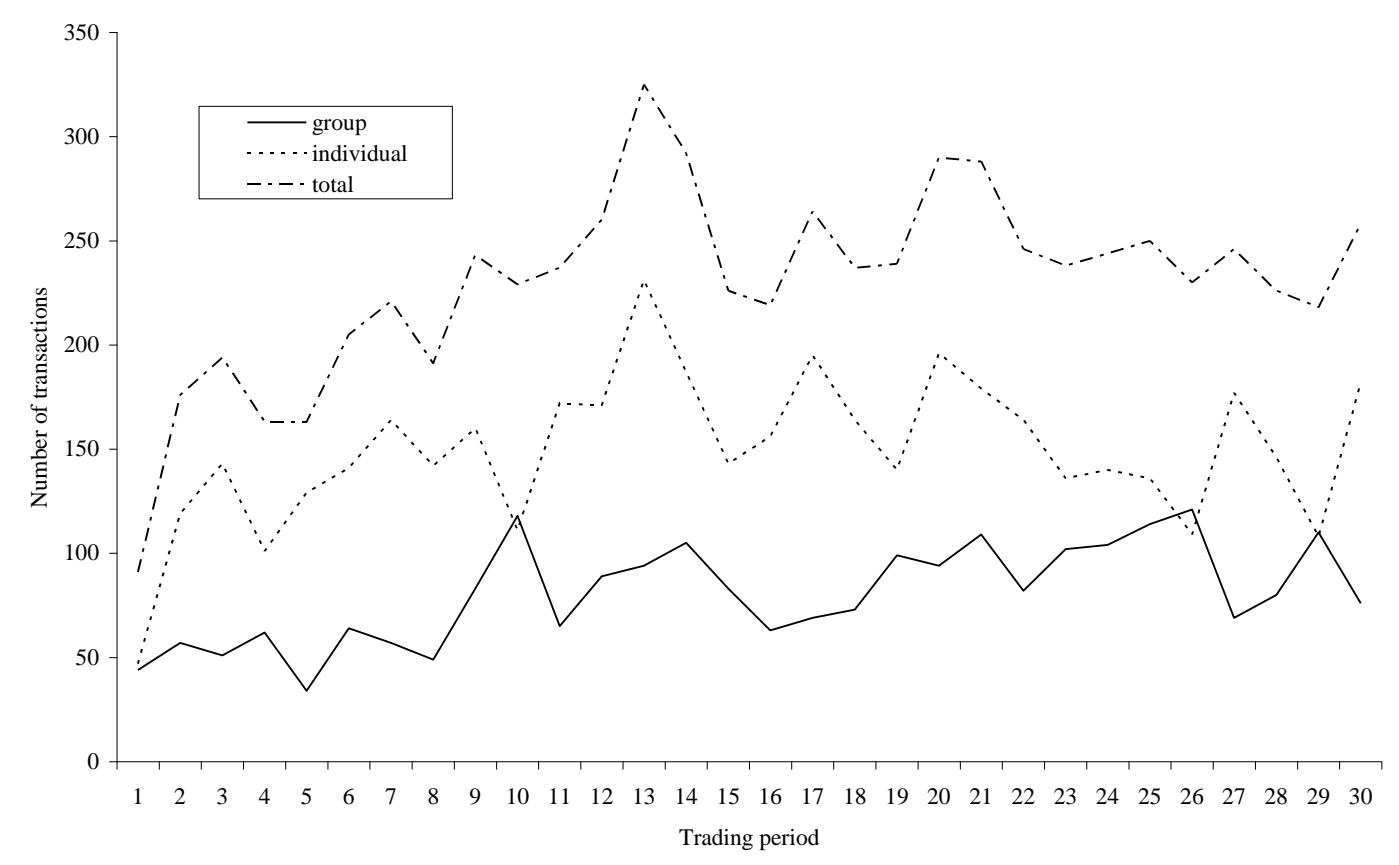

Note: This Figure graphs the average number of trade instructions by 10 -second sub-period from start of a trading period (sub-period 1) to the close of a trading period (sub-period 30). Each trading period lasts 300 seconds (5 minutes) and averages are calculated across all six 5-minute trading periods (2 periods in each of 3 trials). 
Figure 3 - Average of Buy and Sell Prices across 5 Minute Trading Periods

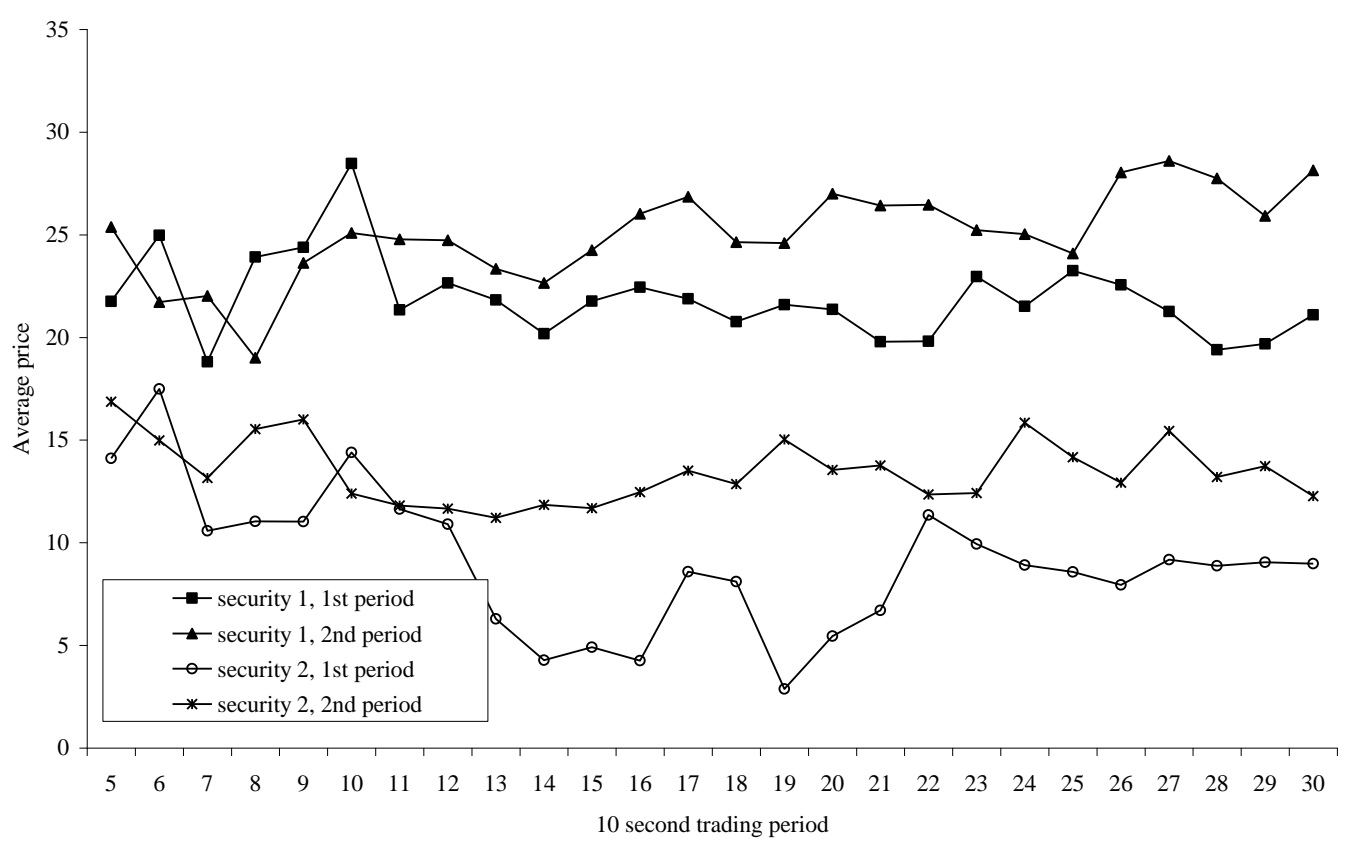

Note: This Figure graphs the average buy/sell price per 10-second interval from the fifth ten-second sub-period to the close of a trading period (sub-period 30). Each trading period lasts 300 seconds (5 minutes) and averages are calculated across all six 5-minute trading periods (2 periods in each of 3 trials). Security 1 refers to ABC and Security 2 is CRA. 
Table 1

\section{Descriptive Statistics}

Panel A: Trading performance and trader characteristics

$\begin{array}{llllll}\text { LATOT_GC } & \text { TOT_GC } & \text { RTOT_GC } & \text { TOT_TRDS } & \text { CONF_I } & \text { UN_TOT_I }\end{array}$

Individual Traders

$(\mathrm{N}=20)$

Mean

1.04

$-5.43$

$-89.82$

Minimum

$-3.99$

32.53

Maximum

4.50

23.40

StdDev

1.84

9.38

Kurtosis

2.07

$-2.59$

26.50
3.00
50.00
15.53
-1.40
-0.19

237.65
33.00
1284.00
277.21
11.30
3.12

17.25

6.65

2.00

1.00

Skewness

$-0.49$

1.21

12.83

28.09

127.00

16.12

5.82

Mean

Maximum

StdDev

2.22

16.29

93.70

4.31

2.04

Kurtosis

$-0.01$

8.53

$-1.15$

$-1.15$

0.03

$-1.00$

Skewness

0.37

2.20

0.09

0.59

$-0.24$

$-0.17$

All Traders

( $\mathrm{N}=37$ )

Mean

1.12

2.96

27.23

186.81

16.73

6.27

Minimum

$-3.99$

$-113.48$

1.50

15.00

2.00

1.00

Maximum

5.48

239.02

53.50

1284.00

25.00

10.00

StdDev

2.00

49.42

15.68

218.14

4.76

2.06

Kurtosis

0.67

$-1.23$

18.05

1.49

$-0.03$

Skewness

2.73

$-0.04$

$-0.79$

$-0.56$

t-statistic

$-0.26$

$-1.12$

$-0.30$

0.72

1.22

Prob (t-test)

(0.80)

(0.27)

(0.76)

1.57

(0.48)

(0.23)

TOT_GC is scaled final cash holdings and is a measure of trading profit as it reflects initial cash endowments, the sum of dividends received from the shares on hand at the end of each 5-minute trading period, plus any interim trading profits and losses. RTOT_GC is the ranked TOT_GC for each trader. LATOT_GC is the natural log of the absolute value of the trading profit for each trader and is used as a proxy for the volatility in TOT_GC. TOT_TRDS is a measure of trading activity and is the number of orders entered into the system, being the total number of the bids, asks, clear bids, clear asks, buys and sells for each trader. CONF_I is a measure of self efficacy or confidence. UN_TOT_I is a measure of understanding.

The $t$-statistic is a test for equality of the means for the individual relative to the team values. The test assumes constant variance between the groups given that we could not reject Levene's test for equality of variance across the two samples. Prob ( $t$-test) is the $t$-test probability and is reported in parentheses below the $t$-statistic. 
Panel B: Correlations between trading performance and trader characteristics

\begin{tabular}{lccccc}
\hline & LATOT_GC & TOT_GC & RTOT_GC & TOT_TRDS & CONF_I \\
\hline TOT_GC & 0.16 & & & & \\
& $(0.36)$ & & & & \\
RTOT_GC & 0.02 & $0.61^{* *}$ & & & \\
& $(0.92)$ & $(0.00)$ & & & \\
TOT_TRDS & 0.25 & $-0.36^{* *}$ & $-0.32^{* *}$ & & \\
& $(0.14)$ & $(0.03)$ & $(0.05)$ & & \\
CONF_I & 0.21 & 0.18 & $0.35^{* *}$ & -0.23 & \\
& $(0.22)$ & $(0.29)$ & $(0.03)$ & $(0.16)$ & \\
UN_TOT_I & $0.30^{*}$ & 0.10 & 0.14 & -0.15 & $0.28^{*}$ \\
& $(0.07)$ & $(0.56)$ & $(0.40)$ & $(0.36)$ & $(0.09)$ \\
\hline
\end{tabular}

Pearson Correlation coefficients for the variables defined in Panel A. The probability from a test for zero correlation is reported in parentheses below the correlation coefficient $(\mathrm{N}=37) . * *(*)$ denotes a result that is statistically significant at a 5\% (10\%) level.

Panel C: Team characteristics

\begin{tabular}{lcccr}
\hline & GRP_ATT & GRP_EFF & COWORK_I & TASK_DIF \\
\hline Mean & 14.48 & 1.85 & 44.00 & 59.81 \\
Minimum & 6.00 & 0.00 & 17.00 & 32.00 \\
Maximum & 22.00 & 2.00 & 63.00 & 100.00 \\
Standard Deviation & 3.29 & 0.44 & 10.58 & 10.25 \\
Kurtosis & 1.57 & 9.82 & 0.51 & 8.47 \\
Skewness & 0.46 & -3.11 & -0.65 & 1.44 \\
No of items & 25.00 & 2.00 & 17.00 & 20.00 \\
Cronbach alpha & 0.76 & 0.52 & 0.86 & 0.66 \\
\hline
\end{tabular}

There are 33 useable responses from 34 questionnaires. GRP_ATT is the sum of the 25 responses to the questions dealing with group attitude. GRP_EFF is the sum of the 2 responses to the questions about group effectiveness. COWORK_I is the sum of the 17 responses to the questions about coworker impressions. TASK_DIF is the sum of the 20 responses to the questions ranking the difficulty of various trading tasks.

Panel D Participant age by group and gender

\begin{tabular}{lcccc}
\hline Gender & Group & Individual & All & t-test prob. \\
\hline Male & 19.94 & 19.90 & 19.92 & 0.95 \\
Count & $(16)$ & $(10)$ & $(26)$ & \\
Female & 22.29 & 20.10 & 21.48 & 0.16 \\
Count & $(17)$ & $(10)$ & $(27)$ & \\
All & 21.15 & 20.00 & 20.72 & 0.18 \\
Count & $(33)$ & $(20)$ & $(53)$ & \\
t-test prob. & 0.15 & 0.67 & 0.13 & \\
\hline
\end{tabular}

53 of 54 participants identified their age and gender. Participants were assigned to individual or team trading by gender. Age was not taken into account in the initial assignment. Numbers in parentheses are participant counts.

$* *(*)$ denotes a result that is statistically significant at a $5 \%(10 \%)$ level. 
Panel E: Correlations between trading performance and team characteristics

\begin{tabular}{|c|c|c|c|c|c|c|c|c|c|}
\hline \multirow{2}{*}{ LATOT_GC } & \multicolumn{9}{|c|}{ TOT_GC LATOT_GCRTOT_GCTOT_TRDS CONF_I UN_TOT_IGRP_ATT GRP_EFFCOWORK_I } \\
\hline & $\begin{array}{c}0.40 \\
(0.13)\end{array}$ & & & & & & & & \\
\hline RTOT_GC & $\begin{array}{l}0.66 \text { ** } \\
(0.01)\end{array}$ & $\begin{array}{c}0.26 \\
(0.33)\end{array}$ & & & & & & & \\
\hline TOT_TRDS & $\begin{array}{l}-0.33 \\
(0.21)\end{array}$ & $\begin{array}{c}0.28 \\
(0.29)\end{array}$ & $\begin{array}{l}-0.42 * \\
(0.10)\end{array}$ & & & & & & \\
\hline CONF_I & $\begin{array}{c}0.28 \\
(0.29)\end{array}$ & $\begin{array}{c}0.15 \\
(0.58)\end{array}$ & $\begin{array}{c}0.35 \\
(0.18)\end{array}$ & $\begin{array}{l}-0.45^{*} \\
(0.08)\end{array}$ & & & & & \\
\hline UN_TOT_I & $\begin{array}{c}0.19 \\
(0.47)\end{array}$ & $\begin{array}{c}0.18 \\
(0.51)\end{array}$ & $\begin{array}{c}0.12 \\
(0.66)\end{array}$ & $\begin{array}{l}-0.38 \\
(0.15)\end{array}$ & $\begin{array}{l}0.53^{* *} \\
(0.04)\end{array}$ & & & & \\
\hline GRP_ATT & $\begin{array}{c}0.05 \\
(0.85)\end{array}$ & $\begin{array}{c}0.06 \\
(0.83)\end{array}$ & $\begin{array}{l}0.56^{* *} \\
(0.02)\end{array}$ & $\begin{array}{l}-0.28 \\
(0.29)\end{array}$ & $\begin{array}{c}0.37 \\
(0.16)\end{array}$ & $\begin{array}{c}0.05 \\
(0.87)\end{array}$ & & & \\
\hline GRP_EFF & $\begin{array}{c}0.12 \\
(0.65)\end{array}$ & $\begin{array}{c}0.14 \\
(0.60)\end{array}$ & $\begin{array}{c}0.26 \\
(0.33)\end{array}$ & $\begin{array}{l}-0.47^{*} \\
(0.06)\end{array}$ & $\begin{array}{l}0.64^{* *} \\
(0.01)\end{array}$ & $\begin{array}{c}0.33 \\
(0.21)\end{array}$ & $\begin{array}{c}0.44 * \\
(0.09)\end{array}$ & & \\
\hline COWORK_I & $\begin{array}{c}0.40 \\
(0.12)\end{array}$ & $\begin{array}{c}0.10 \\
(0.71)\end{array}$ & $\begin{array}{c}0.40 \\
(0.12)\end{array}$ & $\begin{array}{l}-0.47^{*} \\
(0.07)\end{array}$ & $\begin{array}{l}0.68^{* *} \\
(0.00)\end{array}$ & $\begin{array}{l}0.52^{* *} \\
(0.04)\end{array}$ & $\begin{array}{l}0.55^{* *} \\
(0.03)\end{array}$ & $\begin{array}{l}0.58^{* *} \\
(0.02)\end{array}$ & \\
\hline TASK_DIF & $\begin{array}{l}-0.08 \\
(0.78)\end{array}$ & $\begin{array}{c}0.02 \\
(0.93)\end{array}$ & $\begin{array}{l}-0.40 \\
(0.13)\end{array}$ & $\begin{array}{l}-0.18 \\
(0.50)\end{array}$ & $\begin{array}{c}0.09 \\
(0.73)\end{array}$ & $\begin{array}{c}0.13 \\
(0.64)\end{array}$ & $\begin{array}{l}-0.25 \\
(0.36)\end{array}$ & $\begin{array}{c}0.24 \\
(0.36)\end{array}$ & $\begin{array}{l}-0.14 \\
(0.61)\end{array}$ \\
\hline
\end{tabular}

Pearson Correlation coefficients for variables defined in Panels A and C. The probability from a test for zero correlation is reported in parentheses below the correlation coefficient $(\mathrm{N}=16)$.

** (*) statistically significant at the 5\% (10\%) level of significance. 
Table 2

Determinants of Trading Profit

Panel A: Regression using TOT_GC as the dependent variable

\begin{tabular}{lcccc}
\hline & Coefficient & Standard Error & t-statistic & Probability \\
\hline Intercept & 18.2138 & 10.1773 & $1.79^{*}$ & 0.08 \\
TOT_TRDS & -0.0817 & 0.0357 & $-2.29^{* *}$ & 0.03 \\
\hline
\end{tabular}

The estimated regression equation is:

$$
T O T_{-} G C_{i}=\alpha_{0}+\alpha_{1} T O T_{-} T R D S_{i}+\varepsilon_{i}
$$

The measures of fit and diagnostic tests for the regression include R-Square $=0.13$, Standard Error $=$ 46.74 , F-test for statistical significance of the regression probability $=0.028$, Jarque-Bera test statistic for normal distribution probability $=0.000$, White's test statistic for heterscedasticity probability $=$ 0.930 , Ramsey's reset test (1) statistic probability $=0.947$, Ramsey's reset (2) statistic probability $=$ 0.978 .

Panel B: Regression using TOT_GC ranks (RTOT_GC) as the dependent variable

\begin{tabular}{lrccc}
\hline & Coefficient & Standard Error & t-statistic & Probability \\
\hline Intercept & 14.3950 & 9.7874 & 1.47 & 0.15 \\
CONF_I & 0.9713 & 0.5237 & $1.85^{*}$ & 0.07 \\
TOT_TRDS & -0.0183 & 0.0114 & -1.60 & 0.12 \\
\hline
\end{tabular}

The estimated regression equation is:

$$
R T O T_{-} G C_{i}=\alpha_{0}+\alpha_{1} C O N F_{-} I_{i}+\alpha_{2} T O T_{-} T R D S_{i}+\varepsilon_{i}
$$

The measures of fit and diagnostic tests for the regression include R-Square $=0.19$, Standard Error $=$ 14.55 , F-test for statistical significance of the regression probability $=0.030$, Jarque-Bera test statistic for normal distribution probability $=0.362$, White's test statistic for heterscedasticity probability $=$ 0.304 , Ramsey's reset test (1) statistic probability $=0.437$, Ramsey's reset (2) statistic probability $=$ 0.658 .

** (*) is statistically significant at the 5\% (10\%) level of significance. TOT_GC reflects the trading profit of the individual (the sum of dividends, received from the shares on hand at the end of each 5minute trading period, plus trading profits and losses and the value of shares on hand at the end of the game). RTOT_GC consists of the ranks for TOT_GC. CONF_I is a measure of self-efficacy or confidence. TOT_TRDS is the number of orders entered into the system, being the total number of the bids, asks, clear bids, clear asks, buys and sells that the individual or the group make during the total trading period. 
Table 3

\section{Volatility in Trading Profit}

\begin{tabular}{lrccc}
\hline & Coefficient & Standard Error & t-statistic & Probability \\
\hline Intercept & -4.2704 & 1.4800 & $-2.89 * *$ & 0.01 \\
CONF_I & 0.1244 & 0.0658 & $1.89 *$ & 0.07 \\
UN_TOT_I & 0.3489 & 0.1477 & $2.36^{* *}$ & 0.02 \\
TOT_TRDS & 0.0033 & 0.0014 & $2.45^{* *}$ & 0.02 \\
GXTRD & 0.0085 & 0.0034 & $2.49 * *$ & 0.02 \\
\hline
\end{tabular}

The estimated regression equation is:

$$
L A T O T_{-} G C_{i}=\left[\begin{array}{l}
\alpha_{0}+\alpha_{1} C O N F_{-} I_{i}+\alpha_{2} U N_{-} T O T_{-} I_{i} \\
+\alpha_{3} T O T_{-} T R D S_{i}+\alpha_{4}\left(G R P_{-} T R D R_{i} \times T O T_{-} T R D S\right)+\varepsilon_{i}
\end{array}\right.
$$

The measures of fit and diagnostic tests for the regression include R-Square $=0.34$, Standard Error $=$ 1.72 , F-test for statistical significance of the regression probability $=0.008$, Jarque-Bera test statistic for normal distribution probability $=0.775$, White's test statistic for heterscedasticity probability $=$ 0.144 , Ramsey's reset test (1) statistic probability $=0.546$, Ramsey's reset (2) statistic probability $=$ 0.419 .

** (*) is statistically significant at the 5\% (10\%) level of significance. LATOT_GC is the dependent variable and this provides a measure of trading profit volatility. It is the natural $\log$ of the absolute value of TOT_GC which reflects the trading profit of the individual (the sum of dividends, received from the shares on hand at the end of each 5-minute trading period, plus trading profits and losses and the value of shares on hand at the end of the game). CONF_I is a measure of self efficacy or confidence. UN_TOT_I is a measure of participant understanding. TOT_TRDS is the number of orders entered into the system, being the total number of the bids, asks, clear bids, clear asks, buys and sells that the individual or the group make during the total trading period. GRP_TRDR is the group trader dummy variable with value of 1 if the participant is a group and a value 0 if the participant is an individual. GXTRD is the product of GRP_TRDR and TOT_TRDS and it is an interaction term added to the regression to capture the differing response to trading between the groups and the individuals. 
Table 4

\section{Team Characteristics and Trading Profit}

Panel A: regression using TOT_GC ranks (RTOT_GC) as the dependent variable

\begin{tabular}{lrccc}
\hline & Coefficient & Standard Error & t-statistic & Probability \\
\hline Intercept & 12.2440 & 14.1304 & 0.87 & 0.40 \\
TOT_TRDS & -0.0218 & 0.0121 & $-1.81^{*}$ & 0.10 \\
GRP_ATT & 0.9512 & 0.5887 & 1.62 & 0.13 \\
TASK_DIF & -0.2364 & 0.1328 & $-1.78^{*}$ & 0.10 \\
\hline
\end{tabular}

The estimated regression equation is:

$R T O T_{-} G C_{i}=\alpha_{0}+\alpha_{1} T O T_{-} T R D S_{i}+\alpha_{2} G R P_{-} A T T_{i}+\alpha_{31} T A S K_{-} D I F_{i}+\varepsilon_{i}$

The measures of fit and diagnostic tests for the regression include R-Square $=0.52$, Standard Error $=$ 4.04, F-test for statistical significance of the regression probability $=0.028$, Jarque-Bera test statistic for normal distribution probability $=0.491$, White's test statistic for heterscedasticity probability $=$ 0.844 , Ramsey's reset test (1) statistic probability $=0.951$, Ramsey's reset (2) statistic probability $=$ 0.969 .

Panel B: regression using TOT_TRDS as the dependent variable

\begin{tabular}{lrccc}
\hline & Coefficient & Standard Error & t-statistic & Probability \\
\hline Intercept & 374.2287 & 123.6100 & $3.03^{* *}$ & 0.01 \\
COWORK_I & -5.4896 & 2.7668 & $-1.98^{*}$ & 0.07 \\
\hline
\end{tabular}

The estimated regression equation is:

TOT_TRDS $S_{i}=\alpha_{0}+\alpha_{1} C O W O R K_{-} I_{i}+\varepsilon_{i}$

The measures of fit and diagnostic tests for the regression include R-Square $=0.22$, Standard Error $=$ 485.68 , F-test for statistical significance of the regression probability $=0.067$, Jarque-Bera test statistic for normal distribution probability $=0.827$, White's test statistic for heterscedasticity probability $=$ 0.282 , Ramsey's reset test (1) statistic probability $=0.504$, Ramsey's reset (2) statistic probability $=$ 0.807 .

$* *(*)$ is statistically significant at the 5\% (10\%) level of significance. RTOT_GC consists of the ranks for TOT_GC where TOT_GC reflects the trading profit of the individual (the sum of dividends, received from the shares on hand at the end of each 5-minute trading period, plus trading profits and losses and the value of shares on hand at the end of the game). TOT_TRDS is the number of orders entered into the system, being the total number of the bids, asks, clear bids, clear asks, buys and sells that the individual or the group make during the total trading period. GRP_ATT is the sum of the 25 responses to the questions in the first part of the questionnaire dealing with group attitude. COWORK_I is the sum of the 17 responses to the questions in the third part of the questionnaire dealing with co-worker impressions. TASK_DIF is the sum of the 20 responses to the questions in the last part of the questionnaire dealing with task ranking. 